\title{
LOS DERECHOS DE LA NATURALEZA EN LA CONSTITUCIÓN DE LA REPÚBLICA DEL ECUADOR *
}

\section{The rights of nature under the constitution of the republic of ecuador}

Mercedes Cóndor Salazar**

Pontificia Universidad Católica del Ecuador. República del Ecuador.

Recepción: 6 de enero de 2016. Aceptación: 14 de enero de 2016.

DOI:http:/ / dx.doi.org/10.21017/Rev.Repub.2016.v20.a9

\section{RESUMEN}

En este artículo se analiza el proceso de construcción política y jurídica de los derechos de la naturaleza en la Constitución del Ecuador del año 2008. Para ello, primero se realizará un análisis constitucional del régimen de desarrollo y del régimen del buen vivir.

Para abordar el novedoso régimen del buen vivir, se considerarán los principales elementos del sumak kawsay desde la filosofía andina; el buen vivir desde la Constitución. Y desde esta óptica se tendrá en cuenta para ello, como principio normativo, los derechos del buen vivir en la Constitución.

Dicho marco constitucional permitirá descubrir el fundamento constitucional para finalmente considerar los efectos jurídicos del reconocimiento de los derechos de la naturaleza.

Palabras clave: derechos, naturaleza, ambiente, Constitución, buen vivir.

\footnotetext{
* Artículo producto de investigación desarrollada por la autora sobre las nociones y principios que soportan el ordenamiento constitucional ecuatoriano.

** Abogada ecuatoriana, titulada en la Pontificia Universidad Católica del Ecuador. Candidata de Doctora en Derecho Constitucional (Phd) en la Universidad de Buenos Aires. Magíster en Gobernanza, Universidad George Washington. Magister en Derecho Procesal, Universidad Andina Simón Bolívar. Asesora jurídica de la Asamblea Nacional, Corte Constitucional y Ministerio de Justicia y Derechos Humanos del Ecuador.
} 


\begin{abstract}
This article analyses the process of political and legal construction for the right of Nature into the Constitution of Ecuador as of 2008. To do so, we first undertake a constitutional analysis of the development regime and the regime of Good Living.

We consider the key elements of the andean philosophy sumak kawsay and the regime of Good Living from the Constitution point of view. This will allow us to regard Good Living as a normative principle and also the rights of Good Living under the Constitution.

Such constitutional framework will lead us to find out the constitutional underlying principle of the right of Nature and to consider finally the legal effects of the constitutional acknowledgement of the aforementioned right.
\end{abstract}

Key words: rights, nature, environment, Constitution, Good Living.

\title{
1. INTRODUCCIÓN
}

En el marco de la construcción de la Constitución del Ecuador del 2008 (en adelante, Constitución) se empezó a discutir un nuevo modelo de desarrollo que permitiera la unidad en lo diverso y reconociera la experiencia histórica de los pueblos originarios de nuestra sociedad. En esta investigación se analizarán los fundamentos jurídicos del reconocimiento constitucional de los derechos de la naturaleza en el Ecuador.

\section{PROBLEMAS DE INVESTIGACIÓN}

La investigación de la cual es producto el presente artículo estuvo orientada a darle respuesta a un problema: ¿Desde qué fundamentos y principios se orienta el proceso de construcción política y jurídica de los derechos de la naturaleza en la Constitución del Ecuador del año 2008?

\section{ESTRATEGIA METODOLÓGICA}

La investigación tiene un nivel descriptivo e interpretativo, se soportó metodológicamente desde la hermenéutica; el análisis de texto y documental fundamentaron el estudio sobre las respectivas fuentes, diversos autores y escuelas, y sobre el conjunto de disposiciones normativas pertinentes. 


\section{RESULTADOS}

\subsection{El régimen de desarrollo en la Constitución del 2008}

El artículo 275 de la Constitución estable un régimen de desarrollo en el cual se integra un sistema económico-social y solidario orientado al ejercicio de los derechos constitucionales.

El modelo de desarrollo constitucional se basa en cinco principios:

1. Tratar al ser humano como sujeto y como fin.

2. Equilibrio en la relación, sociedad, Estado y mercado.

3. Armonía con la naturaleza.

4. El sumak kawsay.

5. Economía social y solidaridad y plurinacionalidad ${ }^{1}$.

El nuevo modelo económico planteado desde la cosmovisión de los pueblos indígenas y sustentado a lo largo de nuestra Constitución ${ }^{2}$, está basado en el principio del sumak kawsay o buen vivir, el cual será analizado a profundidad más adelante; por ahora, basta establecer que el mismo permite: primero, recuperar la armonía de la persona-comunidad y pacha mama o cosmos (según esta visión, las personas son parte integrante de la pacha mama); segundo, impedir el modelo extractivista y depredador de los recursos naturales; $\mathrm{y}$, tercero, que cualquier actividad de uso de la naturaleza esté limitado a que las generaciones futuras tengan también la posibilidad de usar y gozar en los mismos niveles la naturaleza. Este nuevo modelo requiere del reconocimiento de otros derechos que son fundamentales como lo son: la naturaleza, el derecho a la tierra, el derecho a la soberanía alimentaria, los derechos a la protección de la biodiversidad, el derecho a la protección de los conocimientos ancestrales, etc ${ }^{3}$.

1 Para una mayor referencia sobre el tema, véase Agustín Grijalva y Julio César Trujillo, «El Fundamento Constitucional de la Nueva Economía» en La Tendencia, revista ecuatoriana, No. 10 (Quito: FES/ILDIS, Febrero - Marzo, 2010), pp. 88-93.

2 Como referencia de lo señalado, acotamos que el nuevo modelo de desarrollo constitucional parte del preámbulo de la Constitución que señala: «[...] Decidimos construir: Una nueva forma de convivencia ciudadana, en diversidad y armonía con la naturaleza, para alcanzar el buen vivir, el sumak kawsay [...]». No obstante el título IV de la Constitución (artículos 275-339) desarrolla a profundidad el régimen de desarrollo.

3 Raúl Llasag, «Plurinacionalidad: Una propuesta constitucional emancipadora» en Ramiro Ávila Santamaría, editor, Neoconstitucionalismo y Sociedad (Quito: Ministerio de Justicia, Derechos Humanos y Cultos, 2008) 342 y 343. 


\subsection{El régimen del Buen Vivir}

\subsubsection{El sumak kawsay desde la filosofía andina}

Desde la filosofía andina ${ }^{4}$, el sumak kawsay es un sistema de vida que permite la armonía con la naturaleza, que es todo lo que nos rodea y si es así, tiene vida. En este sentido, el ser humano forma parte de la naturaleza. En suma, desde la filosofía andina, el sumak kawsay es una forma de concepción del mundo que da lugar a un modelo de vida y que se rige por los siguientes principios:

1. Relacionalidad del todo o principio holístico: este afirma que todo está relacionado, vinculado, conectado. Por tanto, para la filosofía andina la relacionalidad del todo, la red de los nexos y vínculos es la fuerza vital de todo lo que existe.

2. Principio de correspondencia: significa que los distintos aspectos, regiones o campos de la realidad se corresponden de una manera armoniosa.

3. Principio de complementariedad: establece que ninguna acción existe por sí sola de manera individual, sino siempre en coexistencia de su complemento específico.

4. Principio de reciprocidad: dice que los diferentes actos se condicionan mutuamente de tal manera que el esfuerzo o una inversión en una acción será compensado por un esfuerzo o una inversión, de la misma magnitud por el receptor ${ }^{5}$.

La traducción literal de sumak kawsay es un error pues no necesariamente significa «buen vivir» o «vivir bien». De ahí que para comprender a cabalidad qué es el sumak kawsay desde la filosofía andina, tomamos en cuenta también lo señalando por Javier Lajo, quien lo define como el encuentro del equilibrio entre los diferentes aspectos de la realidad 6 .

Desde la cosmovisión indígena, la realidad se traduce como «pacha» (todo lo que es), lo que significa «todo lo que existe» en el universo. De esta forma, pacha contiene tanto al tiempo como al espacio y es la base común de los distintos

4 De acuerdo a Raúl Llasag, la filosofía andina se entiende como el conjunto de concepciones, modelos y categorías vividos por el ser humano andino, esto es, la experiencia concreta y colectiva de su ser dentro del universo. Aclara también que la referencia a lo andino no se limita únicamente a la concepción geográfica o topográfica sino también a los ámbitos culturales y étnicos que dieron lugar a una concepción distinta del mundo. Véase Raúl Llasag, «El sumak kawsay y sus restricciones constitucionales», en Foro: revista ecuatoriana de derecho, №12 (Quito: Universidad Andina Simón Bolívar/CEN, 2009), p. 67.

5 Raúl Llasag, "El sumak kawsay y sus restricciones constitucionales», pp. 114-119.

6 Javier Lajo, «Recuperemos el sumckausay -el vivir bien- El wamán, el puma y el Amaru», 2008, en http://alainet.org/active/25273\&lang=es. 
estratos de lo que entendemos como realidad, que son, básicamente, tres: hanaq pacha, kay pacha, y ukhu (o uray) pacha. Por ende, el sumak kawsay es el equilibrio que se alcanza cuando los tres pachas se interrelacionan. Consecuentemente, la realidad del ser, de acuerdo a la filosofía andina, está determinada por una conjugación de fuerzas: la razón, los sentimientos y los instintos. De ahí que desde la cosmovisión andina, el sumak kawsay se alcanza mediante el equilibrio entre el sentir y el pensar bien, que se traduce finalmente en un actuar bien ${ }^{7}$.

\subsubsection{El buen vivir en la Constitución}

La Constitución ecuatoriana no adopta una sola línea con respecto al sumak kawsay, porque en el preámbulo lo considera un principio constitucional pero también lo relaciona como derechos del buen vivir en la parte dogmática; y como régimen del buen vivir, en la parte orgánica ${ }^{8}$.

\subsubsection{El buen vivir como principio normativo en la Constitución}

El preámbulo de la Constitución señala: «Decidimos construir una nueva forma de convivencia ciudadana, en diversidad y armonía con la naturaleza, para alcanzar el buen vivir, el sumak kawsay». Dicho texto implica que el objetivo fundamental del Estado ecuatoriano es alcanzar el sumak kawsay; por lo tanto, sus normas y principios deben ser interpretados en función de alcanzar dicho sumak kawsay9.

El concepto de buen vivir como principio normativo en la Constitución ${ }^{10}$ está dispuesto transversalmente en el texto y debe ser interpretado conjuntamente con otros cambios constitucionales, como es el reconocimiento de la plurinacionalidad, el marcado reconocimiento de la interculturalidad, entre otros ${ }^{11}$.

Tal como lo dice el Plan Nacional para el buen vivir de la Secretaría Nacional de Planificación y Desarrollo, el concepto constitucional del buen vivir forma parte de una larga búsqueda de modelos de vida que han impulsado

7 Carolina Silva, «¿Qué es el buen vivir en la Constitución?», en Ramiro Ávila Santamaría, editor, Constitución del 2008 en el contexto andino (Quito: Ministerio de Justicia, Derechos Humanos y Cultos, 2008) pp. 117 y 119.

8 Raúl Llasag, «El sumak kawsay y sus restricciones constitucionales», p. 119.

9 Ibíd. 120.

$10 \mathrm{Al}$ hablar de principios normativos nos referimos a aquellos que nos permiten interpretar los derechos y aplicarlos. Para una mayor referencia véase: Ramiro Ávila Santamaría, «Los principios de aplicación de los derechos», en Constitución del 2008 en el contexto andino, (Quito: Ministerio de Justicia, Derechos Humanos y Cultos, 2008), p. 67.

11 Carolina Silva, ¿Qué es el buen vivir?, p. 150. 
actores sociales de América Latina durante las últimas décadas. El buen vivir es la apuesta al cambio que promueve un modelo económico incluyente; a su vez, se construye desde las posiciones que reivindican la revisión y reinterpretación de la naturaleza y los seres humanos; finalmente, se construye también desde las reivindicaciones de la igualdad y la justicia social, y desde el reconocimiento y valoración de los pueblos y de sus culturas, saberes y modos de vida ${ }^{12}$.

Para el jurista ecuatoriano Agustín Grijalva, la Constitución en su artículo 275, párrafo 3, deja entender que el buen vivir es un valor, un fin u horizonte que comprende el respeto a la diversidad, el ejercicio de los derechos y responsabilidades constitucionales y otros, como el derecho a la paz consigo mismo y con todo el entorno físico y humano en el que se desenvuelve la vida humana ${ }^{13}$.

En conclusión el buen vivir analizado como principio constitucional responde a un nuevo paradigma conceptual o saber para interpretar a la Constitución que comprende:

Los derechos e instituciones que tienden a dotar a los habitantes del Ecuador para gozar efectivamente de los derechos humanos a vivir en armonía con sus semejantes y con la naturaleza para que esta sea el hábitat de las presentes y futuras generaciones. El conjunto está enunciado en la parte dogmática y, en la parte orgánica que, para garantizar la posibilidad de su ejercicio y el goce efectivo establecen sistemas, políticas y servicios públicos y la planificación para el desarrollo ${ }^{14}$

Finalmente, consideramos que el buen vivir como paradigma tiene el poder de crear derecho; por ende, su introducción tiene que reflejarse en nuevas normas constitucionales que expresen la alteración del paradigma constitucional de $1998^{15}$.

12 Cfr. Secretaría Nacional de Planificación y Desarrollo, Plan Nacional para el Buen Vivir 2009-2013, Quito, SENPLADES, 2009, p. 43. Para una mayor referencia del tema véase Secretaría Nacional de Planificación y Desarrollo, Los nuevos retos de América Latina (Quito: SENPLADES, 2010), p. 27.

13 Agustín Grijalva, Constitucionalismo en el Ecuador (Quito: Corte Constitucional para el periodo de transición, 2011), p. 44. En el mismo sentido véase, también Ramiro Ávila Santamaría, Los derechos y sus garantías. Ensayos críticos, (Quito: Corte Constitucional para el Periodo de Transición, 2012), pp. 99-101.

14 Ramiro Ávila Santamaría, Los derechos y sus garantías. Ensayos críticos, p. 101.

15 Ibíd., p. 151. Sobre este punto, Ana María Larrea sostiene que «la noción del buen vivir permite una importante conexión no lograda en la Constitución anterior, entre la parte dogmática y la parte orgánica de la Carta magna, ya que los derechos logran una articulación sustantiva con la estructura del Estado, su organización territorial, y los denominados régimen de desarrollo y 


\subsubsection{Los derechos del buen vivir en la Constitución}

La Constitución del 2008 incorpora en su parte dogmática, bajo la denominación de «Derechos del buen vivir», a los siguientes derechos: agua y la alimentación, a un ambiente sano, a la comunicación e información, a la cultura y ciencia, educación, hábitat y vivienda, salud, trabajo y seguridad social.

Dentro de la parte orgánica, el régimen del buen vivir articula al sistema nacional de inclusión y equidad social al que lo define como el conjunto de sistemas, instituciones, políticas, normas, programas y servicios que aseguran el ejercicio, garantía y exigibilidad de los derechos y el cumplimiento de los objetivos del régimen de desarrollo.

En los artículos 3.5 y 275, inciso tercero de la Constitución, referentes al buen vivir, se señala que: El buen vivir requerirá que las personas, comunidades, pueblos y nacionalidades, gocen efectivamente de sus derechos, y ejerzan responsabilidades en el marco de la interculturalidad, el respeto a sus diversidades, y de la convivencia armónica con la naturaleza.

De dicho texto se colige que en el preámbulo de la Constitución, la realización del sumak kawsay es el objetivo fundamental del régimen de desarrollo. En definitiva, es concebido como un principio, mientras que en la parte orgánica de la Constitución el sumak kawsay se cree como una meta para alcanzar el régimen de desarrollo, entendiendo este último como la integralidad del sistema económico, político, social, cultural y ambiental ${ }^{16}$.

La Constitución en su artículo 275 señala:

«[...] El buen vivir requerirá que las personas, comunidades, pueblos y nacionalidades gocen efectivamente de sus derechos, y ejerzan responsabilidades en el marco de la interculturalidad, del respeto a sus diversidades, y de la convivencia armónica con la naturaleza [...]». En la misma línea, el artículo 277 de la Norma Magna establece: «[...] Para la consecución del buen vivir, serán deberes generales del Estado: 1. Garantizar los derechos de las personas, las colectividades y la naturaleza $[\ldots] »$.

régimen del buen vivir». Ana María Larrea, «La disputa de sentidos por el buen vivir como proceso contra lo hegemónico», en Secretaría Nacional de Planificación y Desarrollo, en Los nuevos retos de América Latina (Quito: SENPLADES, 2010), p. 21.

16 Ibíd., p. 153 
De lo dicho por la norma constitucional se deduce que el primer elemento que integra el sumak kawsay se refiere a la naturaleza, a la obligación de una convivencia ciudadana en armonía con ella ${ }^{17}$.

Para Eugenio Raúl Zaffaroni, el sumak kawsay, reconocido en nuestra Constitución, no se trata del bien común reducido o limitado a los humanos, sino del bien de todo lo viviente, incluyendo por su puesto a los humanos, entre los que se exige complementariedad y equilibrio, no siendo alcanzable individualmente ${ }^{18}$. Desde esta perspectiva, la invocación de la Pachamama y por supuesto el reconocimiento constitucional de sus derechos, va acompañada de la exigencia de su respeto, que se traduce en la regla básica ética del sumak kawsay (...) que debe regir la acción del Estado y conforme a la que también deben relacionarse las personas entre sí y en especial con la naturaleza ${ }^{19}$.

En definitiva, de conformidad al texto constitucional, se requiere de los derechos de la naturaleza para alcanzar el buen vivir y a la vez el referido buen vivir es el eje referencial de los derechos de la naturaleza.

\section{EL RECONOCIMIENTO CONSTITUCIONAL DE LOS DERE- CHOS DE LA NATURALEZA}

Luego de la finalización del trabajo de la Asamblea Constituyente y la posterior ratificación del pueblo ecuatoriano a la Constitución de Montecristi, el preámbulo y el articulado referente a la naturaleza se incorporó de la siguiente forma:

Preámbulo de la Constitución:

Nosotras y nosotros, el pueblo soberano del Ecuador reconociendo nuestras raíces milenarias, forjadas por mujeres y hombres de distintos pueblos, celebrando a la naturaleza, la pacha mama, de la que somos parte y que es

17 Diana Murcia, «El sujeto naturaleza: elementos para su comprensión» en Alberto Acosta y Esperanza Martínez, compiladores, La Naturaleza con derechos: De la filosofía a la política (Quito: Abya- Yala, 2011), p. 295.

18 Eugenio Raúl Zaffaroni, «La Pachamama y el humano», en Alberto Acosta y Esperanza Martínez, compiladores, La Naturaleza con derechos, p. 106. Véase en el mismo sentido: Eduardo Gudynas, «Seis puntos clave en ambiente y desarrollo», en Alberto Acosta y Esperanza Martínez, compliladores; El buen vivir: Una vía para el desarrollo (Quito: Edic. Abya- Yala, 2009), pp. 103-114.

19 Ibíd., p. 86. 
vital para nuestra existencia, invocando el nombre de Dios y reconociendo nuestras diversas formas de religiosidad y espiritualidad, apelando a la sabiduría de todas las culturas que nos enriquecen como sociedad, como herederos de las luchas sociales de liberación frente a todas las formas de dominación y colonialismo, y con un profundo compromiso con el presente y el futuro, decidimos construir una nueva forma de convivencia ciudadana, en diversidad y armonía con la naturaleza, para alcanzar el buen vivir, el sumak kawsay; una sociedad que respeta, en todas sus dimensiones, la dignidad de las personas y las colectividades; un país democrático, comprometido con la integración latinoamericana -sueño de Bolívar y Alfaro-, la paz y la solidaridad con todos los pueblos de la tierra; $y$, en ejercicio de nuestra soberanía, en ciudad Alfaro, Montecristi, provincia de Manabí, nos damos la presente.

El principal articulado de la Constitución referente a la naturaleza es el siguiente:

Art. 10. Las personas, comunidades, pueblos, nacionalidades y colectivos son titulares y gozarán de los derechos garantizados en la Constitución y en los instrumentos internacionales. La naturaleza será sujeto de aquellos derechos que le reconozca la Constitución.

Art. 71. La naturaleza o Pacha Mama, donde se reproduce y realiza la vida, tiene derecho a que se respete integralmente su existencia y el mantenimiento y regeneración de sus ciclos vitales, estructura, funciones y procesos evolutivos.

Toda persona, comunidad, pueblo o nacionalidad podrá exigir a la autoridad pública el cumplimiento de los derechos de la naturaleza. Para aplicar e interpretar estos derechos se observarán los principios establecidos en la Constitución, en lo que proceda. El Estado incentivará a las personas naturales y jurídicas, y a los colectivos, para que protejan la naturaleza, y promoverá el respeto a todos los elementos que forman un ecosistema.

Para profundizar en las motivaciones que llevaron a los asambleístas constituyentes a realizar dicha incorporación, nos detenemos a analizar una de las actas de la Asamblea Nacional que recoge uno de los debates:

«El jusfilósofo Rudolph Von Ihering decía que el Derecho es «protección de intereses». Lo que nos preocupa y lleva a proteger a la Naturaleza, elevándola de objeto de protección jurídica a sujeto de derecho, es la necesidad de cambiar el paradigma de desarrollo, el enfoque de aproximación legal y la relación que el ser humano tiene con su entorno, a fin de evitar o, al menos, paliar las imprevisibles 
consecuencias que se producirán si mantenemos el sistema de depredación antropocéntrico $[\ldots]^{20}$ »

A la luz del texto constitucional ecuatoriano y de lo señalado en líneas anteriores, las ideas principales que giran en torno a dicho reconocimiento constitucional son: 1) el derecho protege intereses. El derecho entonces es una herramienta de protección; 2) la naturaleza pasa de ser objeto a ser sujeto del derecho en la búsqueda de un nuevo régimen de desarrollo.

En la misma línea, creemos que el reconocimiento constitucional de los derechos de la naturaleza debe ser entendido a la luz de los cambios del constitucionalismo latinoamericano: de ahí que, por ejemplo, la Constitución de Bolivia de 2009 en su preámbulo señala: «Cumpliendo con el mandato de nuestros pueblos, con la fortaleza de nuestra Pachamama y gracias a Dios refundamos Bolivia ${ }^{21}[\ldots] »$.

El artículo 33 de la Constitución boliviana prescribe:

«Las personas tienen derecho a un medio ambiente saludable, protegido y equilibrado. El ejercicio de este derecho debe permitir a los individuos y colectividades de las presentes y futuras generaciones además de otros seres vivos desarrollarse de manera normal y permanente»

De las referencias a la Constitución ecuatoriana y boliviana advertimos que, en primer lugar, el reconocimiento constitucional de los derechos de la naturaleza surge como respuesta a la atención de los daños ambientales producidos en el último siglo cuyas consecuencias han sido reclamadas en diferentes contextos 22 ; en segundo lugar, dicha afirmación no se trata de una incorporación antojadiza y simbólica, de una ocurrencia vernácula, sino de una definición que emerge de la cultura tradicional del pueblo esencial a la idea moderna de la constitución ${ }^{23}$; por último, el nuevo constitucionalismo

20 Asamblea Nacional Constituyente, Informe de Mayoría sobre los Derechos de la Naturaleza, Mesa No. 1 de Derechos Fundamentales y Garantías Constitucionales, Montecristi, 2008.

21 Además se debe destacar que Bolivia ha desarrollado los contenidos constitucionales en leyes específicas sobre el tema promulgando el 15 de octubre del 2012 la «Ley marco de la madre tierra y desarrollo integral para vivir bien» y el 21 de diciembre del 2010 la «Ley de Derechos de la madre tierra».

22 Entre la principal literatura sobre el tema puede consultarse: Lester R. Brown, El Estado del mundo, (México: s/e, 1988); D. J. Speddingo, Contaminación Atmosférica (Barcelona: s/ e, 1981); Roger Garaudy, Ainda é tempo de viver, (Río de Janeiro: s/e, 1980); Ervin Laszlo, La última oportunidad, (Madrid: Círculo, 1985); Theodore Roszak, Persona/Planeta (Madrid: s/e, 1978), entre otros.

23 Eugenio Raúl Zaffaroni, «La Pachamama y el humano», p. 111. 
latinoamericano ${ }^{24}$ opta por proclamar una convivencia con todos los seres vivientes dentro de la tierra denunciando coyunturalmente al fundamentalismo de mercado de las últimas décadas del siglo pasado, aunque desde una perspectiva mucho más amplia y universal. De este modo, la Pachamama ${ }^{25}$ se incorpora al desarrollo constitucional como otro aporte del constitucionalismo latinoamericano al universal ${ }^{26}$.

En definitiva, dotar de derechos a la naturaleza, para nosotros significa, alentar políticamente su paso de objeto a sujeto de derechos, como parte de un proceso centenario de ampliación de los sujetos del derecho, como recordaba ya en 1988 Jorg Leimbacher, jurista suizo. Lo central de los Derechos de la naturale$\mathrm{za}$, es rescatar el «derecho a la existencia» de los propios seres humanos (y por cierto de todos los seres vivos). Este es un punto medular de los derechos de la naturaleza, destacando una relación estructural y complementaria con los derechos humanos ${ }^{27}$.

En el acápite siguiente analizaremos con mayor detalle las implicaciones jurídicas de dicho reconocimiento constitucional; por ahora nos basta resaltar que tiene sentido la incorporación constitucional de los derechos de la naturaleza en una Carta Magna que reconoce un nuevo Régimen de Desarrollo sustentado en el reconocimiento de un principio del buen vivir, en el que tanto seres humanos como naturaleza somos parte de un todo. Es decir, el paradigma del Buen Vivir relaciona íntimamente lo social con lo ambiental,

24 Cfr. Al final de la última década, Bolivia y Ecuador fueron los dos países latinoamericanos que pasaron por transformaciones constitucionales más profundas en el curso de movilizaciones políticas protagonizadas por los movimientos indígenas. Producto de ello sus constituciones presentan conceptos de la filosofía andina, y se resalta el reconocimiento de los derechos de la Pachamama. Boaventura de Sousa Santos, «Cuando los excluidos tienen derecho: justicia indígena, plurinacionalidad e interculturalidad», en Boaventura de Sousa Santos y Agustín Grijalva, editores, Justicia indígena, plurinacionalidad e interculturalidad en Ecuador (Quito: Fundación Rosa Luxemburg/ Abya - Yala, 2012), p. 15.

25 La Pachamama es una deidad protectora, cuyo nombre proviene de las lenguas originarias y significa Tierra, en el sentido de mundo. Es la que todo da, pero como permanecemos en su interior como parte de ella, también exige reciprocidad (...) Cfr. Rodolfo Merlino y Mario Rabey, «Pastores del Altiplano Andino meridional: religiosidad, territorio y equilibrio ecológico» (Cusco: Allpanchis, s/a), pp. 149- 171; Adolfo Columbres, «Seres sobrenaturales de la cultura popular argentina» (Buenos Aires: s/a, s/e), p. 27. Zaffaroni, «La Pachamama y el humano», p. 112.

26 Cfr. Eugenio Raúl Zaffaroni, «La Pachamama y el humano», 107 y 108.

27 Alberto Acosta, «Los derechos de la naturaleza, un lectura sobre el derecho a la existencia» en, Alberto Acosta y Esperanza Martínez, editores, La Naturaleza con derechos: De la filosofía a la política, 343. 
de tal forma que la Pachamama o la Madre Tierra mantenida y protegida se convierte en requisito sine qua non para la existencia del sumak kawsay; en este contexto consideramos que era imperativo el reconocimiento jurídico de la naturaleza, además de ser una exigencia social ${ }^{28}$.

Además, nos fundamentamos en la idea de que todo reconocimiento constitucional de derecho ha significado un proceso de lucha social (a veces de derramamiento de sangre y que todo reconocimiento constitucional de derechos tiene otras implicaciones, aparte de las netamente jurídicas, es decir nos acogemos a lo señalado por Stutzin en el sentido de que el reconocimiento constitucional de los derechos de la naturaleza también implica efecto psicológicos, tal como ha sucedido cada vez que se ha ampliado el ámbito de los derechos humanos ${ }^{29}$. De hecho creemos que el efecto psicológico del reconocimiento de dicho derecho constituirá una función educadora que conciba la personificación de la naturaleza como interlocutora válida del ser humano, y por ende conciba la presencia jurídica de la Pachamama como parte en los conflictos entre hombre y medio ambiente, lo que favorecerá a su vez la búsqueda de la equidad ecológica en las relaciones del ser humano con el mundo natural.

Y concluimos este acápite haciendo nuestras las palabras de Eduardo Gudynas cuando dice: «La cuestión clave es que el reconocimiento de los derechos de la Naturaleza abre las puertas para otro tipo de discusión en la política y la gestión, en la que ya no es necesario demostrar que preservar montañas o selvas es útil para el ser humano o rentable para las empresas» ${ }^{30}$. De ahí que esperamos que la elevación de la categoría jurídica de la naturaleza se traduzca en el mejoramiento de su condición social y, por consiguiente, en la adopción de políticas y normas de conducta que la favorezcan.

28 Mercedes Cóndor y Mario Aguilera, «La iniciativa Yasuní ITT como materialización de los derechos de la naturaleza» en Revista, Derechos Humanos y Derechos de la Naturaleza, $N^{\circ}$ 27, Programa Andino de Derechos Humanos de la Universidad Andina Simón Bolívar en http:/ / www.uasb.edu.ec/padh_contenido.php?cd=2967\&pagpath=1\&swpath= infb\&cd_centro=5\&ug=pu, 2010.

29 Godofredo Stutzin, Un imperativo ecológico: Reconocer los derechos de la naturaleza, (Quito, 20 de junio del 2015) en http://www.opsur.org.ar/blog/wp-content/uploads/2010/ 10/imperativo-ecologico.pdf.

30 Eduardo Gudynas, «Los Derechos de la Naturaleza y la construcción de una justicia ambiental y ecológica en el Ecuador», en Los Derechos de la naturaleza y la naturaleza de sus derechos, (Quito: Ministerio de Justicia, Derechos Humanos y Cultos, 2011) p. 100. 


\section{EFECTOS JURÍDICOS DEL RECONOCIMIENTO CONSTITU- CIONAL DE LOS DERECHOS DE LA NATURALEZA}

La existencia de un derecho significa que su poseedor está facultado para presentarse frente a los tribunales y, en última instancia, los poderes del Estado para ejercer su derecho con relación a otros en caso de que dicho derecho sea desconocido. Dicho de otra forma, los derechos se utilizan como un medio a través del cual definimos los aspectos que la comunidad considera de suficiente relevancia para que sean ejercidos donde sea necesario. Estos derechos pueden existir, por ejemplo, con relación a la propiedad (un poseedor que ha sido despojado de un bien tiene derechos a reclamar su restitución) o con relación a las personas (un menor de edad tiene derecho al cuidado y apoyo de sus padres, los cuales a su vez tienen una obligación legal de cumplir sus obligaciones, por ejemplo) ${ }^{31}$.

Para Eduardo Gudynas, precursor de la propuesta constitucional, el reconocimiento de los derechos de la naturaleza implica que esta posee valores que le son propios, independientes de las valoraciones que le adjudiquen las personas. Ese reconocimiento hace que la naturaleza deje de ser objeto (o un conjunto de objetos) que sirve como simple medio para fines humanos, para volverse sujeto $^{32}$.

Entre los efectos jurídicos más relevantes del reconocimiento constitucional de los derechos de la naturaleza consta como primer punto el que dicho reconocimiento otorga a los derechos validez formal y material, lo que garantiza su protección y defensa, desde la perspectiva del principio de jerarquía normati$\mathrm{va}$, frente a otros derechos constitucionalmente reconocidos, lo que en la práctica

31 Ramiro Ávila Santamaría, El Derecho a la Naturaleza: Fundamentos en La Naturaleza con derechos: De la filosofía a la política, Alberto Acosta y Esperanza Martínez, p. 180.

32 Eduardo Gudynas, «Los derechos de la naturaleza en serio: Respuestas y aportes desde la ecología política» en La Naturaleza con derechos: De la filosofía a la política, Alberto Acosta y Esperanza Martínez, compiladores, 245. Por cuanto Eduardo Gudynas es el autor original de la propuesta destacamos una parte de su biografía Eduardo Gudynas es máster en Ecología Social, Multiversidad Franciscana de América Latina (Montevideo) y de la Pontificia Facultad San Buenaventura de Roma. Ha sido Secretario Ejecutivo del Centro Latino Americano de Ecología Social (CLAES) / Desarrollo, Economía, Ecología, Equidad América Latina. Es autor de más de diez libros que se han publicado en varios países (Argentina, Bolivia, Ecuador, Perú, Costa Rica y España), decenas de capítulos en libros sobre estrategias en desarrollo sostenible en América Latina, sobre la conservación de la Naturaleza, la situación de las áreas rurales, y los límites y posibilidades que ofrecen la integración regional y la globalización para alcanzar la sustentabilidad. Extracto sintetizado de «Eduardo Gudynas, Reseña curricular sintetizada, en http:/ / www.globalizacion.org/gudynas/. 
evitaría que otros derechos - especialmente los de contenido económicoprevalezcan sobre la protección a la naturaleza ${ }^{33}$.

Y como segundo efecto por dicho reconocimiento, le son aplicables los principios de interpretación y aplicación de los derechos reconocidos en el artículo 11 de la Constitución ${ }^{34}$; es decir, por su reconocimiento constitucional, los derechos de la naturaleza son plenamente justiciables, de directa e inmediata aplicación por y ante cualquier servidora o servidor público, administrativo o judicial, de oficio o a petición de parte, garantizando las condiciones necesarias para su pleno reconocimiento y ejercicio, sin restringirlos y promoviendo el desarrollo progresivo de sus contenidos.

Sobre este asunto, Agustín Grijalva sostiene que los derechos de la naturaleza al hallarse establecidos en la Constitución ecuatoriana tienen necesariamente el efecto de elevar los estándares de protección ambiental ${ }^{35}$. De ahí que, en virtud de la positivización de los derechos de la naturaleza el daño ambiental para ser tal, no requiere implicar una afectación inmediata y directa sobre los seres humanos ${ }^{36}$.

Es decir, no se requiere una violación patente del derecho humano a un medio ambiente sano, sino la sola disrupción dañosa de los procesos naturales de los

33 Ricardo Crespo Plaza, «La naturaleza como sujeto de derechos: ¿Símbolo o realidad jurídica?», en Iuris Dictio, Revista del Colegio de Jurisprudencia de la Universidad San Francisco de (Quito, s/e, 2009), p. 33.

34 Para Ramiro Ávila Santamaría una de las innovaciones importantes en nuestra Constitución en la teoría de los derechos es que el artículo 11.6 de nuestra Constitución reconoce que todos los principios y los derechos son inalienables, irrenunciables, indivisibles, interdependientes y de igual jerarquía, esto quiere decir que cualquier clasificación sobre derechos humanos no implica jerarquización alguna. Ávila, «Los principios de aplicación de los derechos en la Constitución del 2008», p. 61.

35 Para una mayor referencia el artículo 395 de la Constitución establece los principios ambientales, entre los que se destaca que las políticas de gestión ambiental se aplicarán en forma transversal y serán de obligatorio cumplimiento por parte del Estado en todos sus niveles y por todas las personas naturales o jurídicas en el territorio nacional; y que en caso de duda sobre el alcance de las disposiciones legales en materia ambiental, éstas se aplicarán en el sentido más favorable en la protección de la naturaleza.

36 Decimos afectación sería directa e inmediata porque en el paradigma biocéntrico, el daño ambiental siempre supone una afectación a los seres humanos, aunque fuere indirecta o mediata, dada la concepción de la especie humana, en el marco de esta paradigma, como integrada al ecosistema tierra. En consecuencia, en último análisis los derechos de la naturaleza son también derechos humanos en cuanto apuntan a las condiciones naturales necesarias para la sobrevivencia de la especie humana. Agustín Grijalva, Régimen Constitucional de Biodiversidad, Patrimonio Natural y Ecosistemas Frágiles; y, Recursos Naturales Renovables, p. 7. 
propios ecosistemas, que aun sin afectar supuestamente a los seres humanos, constituye una violación a la Constitución ${ }^{37}$.

A nivel procesal, la positivización de los derechos de la naturaleza conlleva efectos relevantes, fundamentalmente en cuanto a la legitimación activa y a la inversión de la carga procesal. Sobre los efectos en la legitimación activa, Raúl Llasag sostiene que la consecuencia de que cualquiera puede accionar en defensa de la naturaleza, sin que sea menester invocar -y menos probar- la condición de damnificado, provocará que diferentes personas, según sus simpatías con los entes naturales no humanos, ejerzan acciones en su defensa [...]. Y lo más importante es que, al reconocerle a la naturaleza el carácter de sujetos de derechos adquiere esta la condición de tercero agredido cuando se la ataque ilegítimamente y, por ende, habilita el ejercicio de la legítima defensa en su favor (legítima defensa de terceros) ${ }^{38}$.

Y sobre los efectos de la inversión de la carga prueba, Agustín Grijalva bien señala que el efecto jurídico del reconocimiento de los derechos de la naturaleza es que ya no se requiere probar que el daño al ambiente afecta a los seres humanos porque el reconocimiento referido lleva implícito la noción de que la naturaleza y los seres humanos formamos un todo ${ }^{39}$.

Por todo lo expuesto se puede sostener que la Constitución ecuatoriana rompe los moldes tradicionales de las instituciones procesales de la legitimación y la inversión de la carga de la prueba en materia ambiental. Finalmente hay que señalar que dichas instituciones aún no han sido desarrolladas en la legislación ambiental del Ecuador puesto que en su mayoría las leyes que actualmente regulan el tema procesal ambiental en nuestro país fueron expedidas antes de la Constitución del 2008.

\section{CONCLUSIONES}

El nuevo modelo económico constitucional planteado desde la cosmovisión de los pueblos indígenas ecuatorianos y sustentado a lo largo de la Constitución, está basado en el principio del sumak kawsay que permite: primero, recuperar la

37 Agustín Grijalva considera que esta noción objetiva o institucional del daño ambiental no es en realidad tan extraña al Derecho como lo atestigua la existencia de delitos ambientales en que se sancionan conductas destructivas del ambiente aunque no se afecte directa e inmediatamente a la población humana.

38 Raúl LLasag, Derechos de la Naturaleza: Una mirada desde la filosofía andina y la Constitución, (Quito: Ministerio de Justicia, Derechos Humanos y Cultos), p. 76.

39 Agustín Grijalva, Constitucionalismo en el Ecuador, p. 7. 
armonía de la persona-comunidad y pacha mama o cosmos; segundo, impedir el modelo extractivista y depredador de los recursos naturales; $y$, tercero, que cualquier actividad de uso de la naturaleza esté limitado a que las generaciones futuras tengan también la posibilidad de usar y gozar en los mismos niveles la naturaleza.

Con base al análisis del régimen de desarrollo y el principio del buen vivir, colegimos que la Constitución ecuatoriana consagra un nuevo paradigma en materia ambiental al definir a la naturaleza como sujeto de derechos. Este paradigma garantiza la tutela efectiva de los derechos ambientales por medio de varios mecanismos y principios constitucionales como: el principio In dubio pro natura, la inversión de la carga de la prueba en materia ambiental, la imprescriptibilidad de las acciones ambientales, la acción popular para exigir el cumplimiento de los derechos de la naturaleza, la consulta previa y, la responsabilidad objetiva por los daños ambientales.

Por lo tanto, el reconocimiento constitucional de los derechos de la naturaleza tiene fundamento jurídico por cuanto se basa en el nuevo Régimen de Desarrollo y el principio del buen vivir o sumak kawsay en el que, tanto seres humanos como naturaleza somos parte de un todo. Es decir, reconoce el paradigma del buen vivir en el cual se relaciona íntimamente lo social con lo ambiental, de tal forma que la Pachamama o la Madre Tierra mantenida y protegida se convierte en requisito sine qua non para la existencia del sumak kawsay.

Finalmente reconocemos que la Constitución ecuatoriana al reconocer a la Naturaleza como sujeto de derechos rompe con los paradigmas que tradicionalmente han regido la normativa ambiental pues se consagran varios principios constitucionales para su efectiva tutela. Sin embargo, en la actualidad el Ecuador no cuenta con una legislación secundaria acorde a los postulados del nuevo paradigma que la Constitución prevé en materia ambiental por cuanto los mecanismos procesales que existen resultan insuficientes para proporcionar una adecuada tutela a los derechos de la naturaleza.

\section{REFERENCIAS}

ACOSTA, Alberto (2011). «Los derechos de la naturaleza, una lectura sobre el derecho a la existencia» en: Alberto Acosta y Esperanza Martínez, editores, La Naturaleza con derechos: De la filosofía a la política. Quito.

ÁVILA SANTAMARÍA, Ramiro (2012). Los derechos y sus garantías. Ensayos críticos . Quito: Corte Constitucional para el Periodo de Transición. 
ÁVILA SANTAMARÍA, Ramiro (2008). «Los principios de aplicación de los derechos», en Constitución del 2008 en el contexto andino. Quito: Ministerio de Justicia, Derechos Humanos y Cultos.

ÁVILA SANTAMARÍA, Ramiro (2011). El Derecho a la Naturaleza: Fundamentos en La Naturaleza con derechos: De la filosofía a la política, Alberto Acosta y Esperanza Martínez. Quito.

CÓNDOR, Mercedes y AGUILERA, Mario (2010). «La iniciativa Yasuní ITT como materialización de los derechos de la naturaleza» en Revista, Derechos Humanos y Derechos de la Naturaleza, $N^{\circ}$ 27, Programa Andino de Derechos Humanos de la Universidad Andina Simón Bolívar en http://www.uasb.edu.ec/padh_ contenido.php?cd= 2967\& pagpath=1\&swpath=infb\&cd_centro=5\&ug=pu.

CRESPO PLAZA, Ricardo (2009). «La naturaleza como sujeto de derechos: ¿Símbolo o realidad jurídica?», en Iuris Dictio, Revista del Colegio de Jurisprudencia de la Universidad San Francisco. Quito, s/e.

GRIJALVA Agustín y TRUJILLO Julio César (2010). «El Fundamento Constitucional de la Nueva Economía» en La Tendencia, revista ecuatoriana, No. 10. Quito: FES/ ILDIS, Febrero - Marzo.

GRIJALVA Agustín (2011). Constitucionalismo en el Ecuador. Quito: Corte Constitucional para el periodo de transición.

GUDYNAS, Eduardo (2011). «Los derechos de la naturaleza en serio: Respuestas y aportes desde la ecología política» en La Naturaleza con derechos: De la filosofía a la política, Alberto Acosta y Esperanza Martínez, compiladores. Quito.

GUDYNAS, Eduardo (2011). «Los Derechos de la Naturaleza y la construcción de una justicia ambiental y ecológica en el Ecuador », en Los Derechos de la naturaleza y la naturaleza de sus derechos. Quito: Ministerio de Justicia, Derechos Humanos y Cultos.

LAJO, Javier (2008). «Recuperemos el sumckausay -el vivir bien- El wamán, el puma y el Amaru», en http://alainet.org/active/25273\&lang=es.

LARREA, Ana María (2010). «La disputa de sentidos por el buen vivir como proceso contra hegemónico», en Secretaría Nacional de Planificación y Desarrollo, en Los nuevos retos de América Latina. Quito: SENPLADESO.

LLASAG Raúl (2008). «Plurinacionalidad: Una propuesta constitucional emancipadora» en Ramiro Ávila Santamaría, editor, Neoconstitucionalismo y Sociedad. Quito: Ministerio de Justicia, Derechos Humanos y Cultos. 
LLASAG Raúl. Derechos de la Naturaleza: Una mirada desde la filosofía andina y la Constitución. Quito: Ministerio de Justicia, Derechos Humanos y Cultos.

LLASAG Raúl. (2009). «El sumak kawsay y sus restricciones constitucionales», en Foro: revista ecuatoriana de derecho, N 12. Quito: Universidad Andina Simón Bolívar/ CEN.

MURCIA, Dunia (2011). «El sujeto naturaleza: elementos para su comprensión» en Alberto Acosta y Esperanza Martínez, compiladores, La Naturaleza con derechos: De la filosofía a la política. Quito: Abya- Yala.

SECRETARÍA NACIONAL DE PLANIFICACIÓN Y DESARROLLO (2010). Los nuevos retos de América Latina. Quito: SENPLADES.

SILVA, Carolina (2008). «¿Qué es el buen vivir en la Constitución?», en Ramiro Ávila Santamaría, editor, Constitución del 2008 en el contexto andino. Quito: Ministerio de Justicia, Derechos Humanos y Cultos.

STUTZIN, Godofredo (2015). Un imperativo ecológico: Reconocer los derechos de la naturaleza. Quito, 20 de junio, en http:/ / www.opsur.org.ar/blog/wp-content/uploads/ 2010/10/imperativo-ecologico.pdf.

ZAFFARONI, Eugenio Rául (2009). «La Pachamama y el humano», en Alberto Acosta y Esperanza Martínez, compliladores; El buen vivir: Una vía para el desarrollo. Quito: Edic. Abya- Yala. 